\title{
Botulinum Toxin Type A in Severe Diabetic Neuropathy
}

Hossam Egila, Mohamed Gomaa, Ayman Abdel-naby, Mohammad S. Shehab El-din

\begin{abstract}
Department of Neurology
Mansoura university

Hospital, EL Mansoura, Egypt

Correspondence to: Hossam Egila, Department of Neurology Mansoura university Hospital, EL Mansoura, Egypt

Email:

drhosamegila@gmail.com
\end{abstract}

Received: 21 August 2020

Accepted: 11 September 2020

\begin{abstract}
:
Background: Managing patients with severe diabetic neuropathy is a great challenge, many lines of treatment are available but there are many patients that cannot tolerate large doses of these medications or not responding or contraindicated to use these lines. Recent experimental evidence suggests that botulinum toxin type A (BTX-A) may have role in management of neuropathic pain. Methods:42 patients with diabetes(22 patients injected Botox and 20 patients placebo) were enrolled in this study. Patients were assessed using VAS and PSQI scale at 0,1,4,12 weeks. Results: significant reduction in VAS 1,4- and 12-weeks post injection in patients injected with Botox in comparison to patients injected with placebo $\mathrm{p}(.047, .001$ and .000) respectively. No significant improvement in PSQI in patient injected with Botox as compared to patients injected with placebo. Conclusion: Botulinum Toxin (A) is effective in sever diabetic neuropathy and may be an alternative way in management of severe diabetic neuropathy.
\end{abstract}

Key words: Botulinum toxin type (A), diabetic neuropathy, neuropathic pain.

\section{Introduction}

Diabetic peripheral neuropathy (DPN) is a common complication of diabetes affecting $66 \%$ of patients with insulin-dependent diabetes mellitus and $59 \%$ of patients with non-insulin-dependent diabetes mellitus (1) . Painful diabetic neuropathy (PDN) affects $16 \%$ of patients with diabetes, and it is frequently unreported (12.5\%) and more frequently untreated (39\%)

Neuropathic pain has a substantial impact on quality of life, especially by causing considerable sleep disruption, daily activities, and enjoyment of life. Chronic neuropathic pain is present in $13-26 \%$ of 
diabetic patients. (3-6) Chronic DPN with persistent or episodic pain that typically may worsen at night, and improve during walking, is localized predominantly in the feet.

The pain is often described as a deep-seated ache, but there may be superimposed lancination, or it may be of burning thermal quality (7) More than $25 \%$ of patients with type 2 diabetes have neuropathic pain syndromes. The pain, usually attacking the distal extremities, results in disturbed sleep and diminished quality of life (4).

Although many symptomatic therapies are available for neuropathic pain, including antidepressants, anticonvulsants, and opioids, as well as some novel strategies, many of these remain unsatisfactory. A small number of patients do not tolerate the adverse events (8). Botulinum Neurotoxins (BTX-A) are used in treatment of spasticity and glandular hyperactivity but also found to suppress both nociceptor sensitization and neuropathic pain such as trigeminal neuralgia and carpal tunnel syndrome (8, 9).

This effect is due to the inhibition of neurotransmitter release as serotonin, dopamine, noradrenaline, glutamate, gamma aminobutyric acid (GABA), enkephalin, glycine, substance P, ATP, calcitonin gene-related peptide (CGRP), somatostatin, and neuronal nitric oxide synthase. In this study, we evaluated the effects of intradermal, rather than intramuscular, BTX- A injections on pain symptoms in patients with diabetic neuropathic pain.

\section{Patients and Methods}

This case control study was done January 2012 - March 2013, 42 patients with diabetes (22 patients injected BTX-A and 20 patients placebo) in Mansoura University hospitals, and outpatient clinics of Neurology.

Prior to the initiation of the study, all procedures was reviewed by ethical and research committee, Mansoura University. Written informed consents were obtained from all participants, they were informed about the nature and objectives of the study.

These patients were required to have a history of diabetes mellitus and neuropathic pain in both feet with trial of traditional treatment for enough period with maximum tolerable dose or contraindication to these treatments. Diabetic neuropathy was diagnosed by history and nerve conduction study examinations. 


\section{Exclusion criteria:}

The exclusion criteria included common causes of pain in both lower limbs peripheral arterial occlusion disease, infection and any lumbar-sacral radiculopathy through history, local examination for signs of inflammation, arterial pulsation and examination of back neurological examination to rule out disc prolapse also patients underwent investigations to exclude other causes ( $\mathrm{X}$ Ray lumboscaral and arterial suppler on both Lower limbs). Patients stop medication for pain before and after injection to avoid their bias.

\section{Methods}

Patients with severe diabetic neuropathy (VAS $\geq 7$ ) were injected intradermally with BTX-A 50 units in each foot in 12 points $3 * 4$ across dorsum of the foot. The distance between them is approximately equal, and also in some target points mentioned by the patient shortly around ankle or above it (maximum three or four points), for the control group patients injected with saline $0.9 \%$ in the same points and with the same manner as patients group.

\section{ASSESSMENT}

Visual analogue scale (VAS) and Pittsburgh Sleep Quality Index (PSQI), at 0, 1- week, 4-weeks, 12-weeks, and 12- week intervals. For VAS measurement, the study nurse asked the patients to point out the current pain severity during the last day on a rule with $0.0-10.0$ scales $(0.0=$ no pain, $10.0=$ unbearable pain). Changes in VAS score within 12 weeks are the primary endpoint and changes in sleep quality are the secondary endpoints for this study.

\section{Statistical analysis}

The collected patients' data were tabulated and analyzed using the SPSS version 16 software (SPSS Inc., Chicago, ILL company). Categorical data were expressed as number and $\%$ and analyzed using ' $\chi$, and Fisher's exact tests. Continuous variables were presented as mean and SD and analyzed using 'Student's $t$-test'. The accepted level of significance in this work was $0.05 \quad(P<0.05$ was considered significant).

\section{Results}

22 patients 13 male $(59.1 \%)$ and 9 female (40.9\%) were injected with Botox and 20 patients 10 male $(50 \%)$ and 10 female $(50 \%)$ were injected placebo mean age $(62.73 \pm 5.71)$ for botox group and $(62.95 \pm 5.81)$ for the control group (table 1 , 
Before injection VAS was $(8.73 \pm 0.46)$ for patients group and $(8.45 \pm 0.60)$ for control group, after 1 week VAS $(7.45 \pm 0.86)$ for patients group and $(7.95 \pm 00.69)$ for control group, after 4 weeks VAS $(5.95 \pm 0.95)$ for patients group and $(6.85 \pm 0.67)$ for control group and after 12 weeks VAS $(5.14 \pm 1.08)$ for patients group and $(6.40 \pm 0.6)$ for control group (table 3).

During follow up of patients injected with botulinum toxin and placebo there was a significant reduction in VAS 1,4 and 12 weeks post injection, in patients injected with Botox in comparison to patients injected with placebo $(\mathrm{p}<0.05) \quad(0.047$, 0.001 and 0.000 ) respectively as regard improvement of symptoms of burning, evoked pain to brush (table 4) No significant improvement in PSQI 1,4 and 12 weeks post injection in patient injected with BTX-A as compared to patients injected with placebo $(\mathrm{p}<0.05)(0.62,0.64$ and 0.6 ) respectively (table 5)

Table 1: Demographic data of patients and control group

\begin{tabular}{|c|c|c|c|c|c|}
\hline & & & Patients & Control & Total \\
\hline \multirow[t]{4}{*}{ Sex } & Female & Count & 9 & 10 & 19 \\
\hline & & $\%$ within group & $40.9 \%$ & $50 \%$ & $45.2 \%$ \\
\hline & Male & Count & 13 & 10 & 23 \\
\hline & & $\%$ within group & $59.1 \%$ & $50 \%$ & $54.8 \%$ \\
\hline Total & & & 22 & 20 & \\
\hline
\end{tabular}

Table 2: Age of patients and control group

\begin{tabular}{llccc}
\hline & & Number & Mean & Std. Deviation \\
\hline \multirow{2}{*}{ Age } & Patients & 22 & 62.73 & 5.71 \\
& Control & 20 & 62.95 & 5.81 \\
\hline
\end{tabular}


Table 3: Comparison of the effects of BTX-A and placebo on (VAS) at $0,1,4,12$ weeks post injection

\begin{tabular}{|c|c|c|c|c|c|}
\hline & & Number & Mean & & \\
\hline \multirow[t]{2}{*}{ VAS 0} & Patients & & 22 & 8.73 & 0.46 \\
\hline & Control & & 20 & 8.45 & 0.60 \\
\hline \multirow[t]{2}{*}{ VAS 1} & Patients & & 22 & 7.45 & 0.86 \\
\hline & Control & & 20 & 7.95 & 0.69 \\
\hline \multirow[t]{2}{*}{ VAS 4} & Patients & & 22 & 5.95 & 0.95 \\
\hline & Control & & 20 & 6.85 & 0.67 \\
\hline \multirow[t]{2}{*}{ VAS 12} & Patients & & 22 & 5.14 & 1.08 \\
\hline & Control & & 20 & 6.40 & 0.6 \\
\hline
\end{tabular}

Table 4: Comparison of the effects of BTX-A and placebo on (VAS) at 0, 1, 4, 12 weeks post injection

\begin{tabular}{ll}
\hline Visual analogue scale & P-value \\
\hline VAS 0 & 0.105 \\
VAS 1 & 0.047 \\
VAS 4 & 0.001 \\
VAS 12 & 0.000 \\
\hline
\end{tabular}

Table 5: Comparison of the effects of BTX-A and placebo on (PSQI) at 0, 1, 4, 12 weeks post injection

\begin{tabular}{cc}
\hline Pittsburgh Sleep Quality Index & P-value \\
PSQI 0 & 0.46 \\
PSQI 1 & 0.62 \\
PSQI 4 & 0.64 \\
PSQI 12 & 0.6 \\
\hline
\end{tabular}




\section{Discussion}

The analgesic effects of BTX-A in DPN in both animal and human population have been studied $(10,11,12)$. The advantages of BTX-A administration in server diabetic neuropathy over ordinary treatment due to its efficacy, extended duration of its analgesic effects, well tolerability and less side-effects (10). Although there were still limited number of trials regarding the usefulness of BTX-A administration for treatment of DPN but most of existing studies supported its effectiveness in this regard.

An important issue in our study is the application on severe pain associated with diabetic neuropathy which is specifically considered in this study as those patients has long history of medical treatment and most of them are resistant to treatment. The beneficial effect of BTX-A is believed to result from the blockade of presynaptic nerve terminals releasing acetylcholine, but its exact analgesics effect was not determined yet (14-16).

Ranoux and co-workers, suggested that the analgesics effect of BTX-A may be due to its local peripheral effect on nociceptive fibers (11). That study conducted in France, was done on the analgesics effects of onetime intradermal administration of BTX-A on DPN pain in 29 diabetic patients. The outcome was reported at baseline, 4, 12 and 24 weeks. They indicated that BTX-A have a significant effect on pain intensity of DPN from 2 to 14 weeks. For the 1st time, they concluded that BTX-A independent of its action on muscle tone have an analgesic effect on DPN pain. Hence, chronic DPN related pain considered as a novel indication for intradermal BTX-A injection (10). In another recent study, (14) done using multiple intradermal BTX-A injection, revealed that it has significant improvement in VAS after 3 weeks of injection of patients with DPN. Yuan et al. (12) in Taiwan, in a double-blind crossover trial have investigated the effect of intradermal BTX-A for DPN pain in 20 patients. They showed that using VAS, BTX-A significantly reduced DPN pain during a 12 -week period. Nearly $44.4 \%$ of their studied patients reported VAS reduction regarding DPN pain within 3 months.[12]

Our study showed similar results regarding VAS at 4 weeks and 12 weeks. but with PSQI no significant changes, whereas in the study of Yuan and colleague (12), there was significant improvement in the PSQI which may be due to the persistence of some pain modalities as our study didn't include scale that assess different pain modalities and pain in diabetic neuropathy 
may be due to any type which interfere with sleep quality.

Our results regarding the PSOI is not contradictory to the significant improvement in VAS as this may be explained by the psychological feedback of undergoing a new procedure and a new hope to relief pain and the denial to face the fact that, no hope. Also, it seems that this type of treatment improves some modalities of pain and not the other which may be masked during a day and become more prominent at night but when discussing patient he evaluates the overall improvement.

So, we recommend, further application studies on a larger sample of patients with longer period of follow up and the use of more detailed scales for the different modalities of pain for better evaluation.

\section{Conclusion}

The use of BTX-A in patients with severe diabetic neuropathic pain may be a new hope for patients resistant to medical treatment or have contraindications to it. Our study revealed significant good results with intradermal injection of BTX-A with minimal side effects and relative less contraindications compared with other drugs but still we need a study on a wide range scale.

\section{References}

1.Jaiswal M, Divers J, Dabelea D, Isom S, Bell RA, Martin CL, et al. Prevalence of and risk factors for diabetic peripheral neuropathy in youth with type 1 and type 2 diabetes: SEARCH for Diabetes in Youth Study. Diabetes care. 2017;40(9):1226-32.

2.Djibril AM, Mossi EK, Djagadou AK, Balaka A1, Tchamdja T, Moukaila R

"Epidemiological, diagnostic, therapeutic and evolutionary features of diabetic foot: a study conducted at the Medico- surgical Clinic, University Hospital Sylvanus Olympio in Lomé," Pan Afr Med J. 2018;30:4.

3.Daousi C, MacFarlane IA, Woodward A, Nurmikko TJ, Bundred PE, Benbow SJ. Chronic painful peripheral neuropathy in an urban community: a controlled comparison of people with and without diabetes. Diabet Med 2004;21: 976982.

4.Davies M, Brophy S, Williams R, Taylor A. The prevalence, severity, and impact of painful diabetic peripheral neuropathy in type 2 diabetes. Diabetes Care 2006;29: 1518-1522.

5.Ziegler D, Rathmann W, Dickhaus T, Meisinger C, Mielck A; for the KORA Study Group. Prevalence of polyneuropathy in prediabetes and diabetes is associated with abdominal obesity and macroangiopathy: the MONICA/KORA Augsburg Surveys S2 and S3. Diabetes Care 2008; 31:464469.

6. Galer BS, Gianas A, Jensen MP. Painful diabetic neuropathy: epidemiology, pain description, and quality of life. Diabetes Res Clin Pract 2000;

47:123-128

7. Pop-Busui R, Boulton AJ, Feldman EL, Bril V, Freeman R, Malik RA, et al. Diabetic neuropathy: a 
position statement by the American Diabetes

Association. Diabetes care. 2017;40(1):136-54.

8. Argoff CE. A focused review on the use of botulinum toxins for neuropathic pain. Clin J Pain $2002 ; 18(6$ suppl):

S177181.

9. Piovesan EJ, Teive HG, Kowacs PA, Della

Coletta MV, Werneck LC, Silberstein SD. An open study of botulinum A toxin treatment of trigeminal neuralgia. Neurology 2005; 65:1306-1308.

10.Bossowska A, and Majewski M. Botulinum toxin type A induced changes in the chemical coding of dorsal root ganglion neurons supplying the porcine urinary bladder. Pol. J. Vet. Sci 2012; 15, 345 - 353.

11. Ranoux D, A al N, Morain F, Bouhassira D. Botulinum toxin type $\mathrm{A}$ induces direct analgesic effects in chronic neuropathic pain. Ann Neurol 2008; 64:274-83.
12. Yuan RY, Sheu JJ, Yu JM, Chen WT, Tseng IJ, Chang $\mathrm{HH}$, et al. Botulinum toxin for diabetic neuropathic pain: A randomized double-blind crossover trial. Neurology 2009; 72:1473-8. 13. Argo CE. A focused review on the use of botulinum toxins for neuropathic pain. Clin J Pain 2002;18: S177-81.

14. Majid Ghasemi, Maryam Ansari, Keivan Basiri, and Vahid Shaigannejad The effects of intradermal botulinum toxin type a injections on pain symptoms of patients with diabetic neuropathy J Res Med Sci. Feb 2014; 19(2): 106-111.

15. Aoki KR. Review of a proposed mechanism for the antinociceptive action of botulinum toxin type A. Neurotoxicology 2005; 26:785-93. 16. Huang J, Han C, Estacion M, Vasylyev D, Hoeijmakers J , Gerrits M, et al. Gain-offunction mutations in sodium channel $\mathrm{Na}(\mathrm{v}) 1.9$ in painful neuropathy. Brain 2014; 137(Pt 6): 1627-42.

To cite this article: Hossam Egila, Mohamed Gomaa, Ayman Abdel-naby, Mohammad S. Shehab El-din. Botulinum Toxin Type A in Severe Diabetic Neuropathy. BMFJ 2020;37(3):723-730, DOI: $10.21608 / \mathrm{bmfj} .2020 .40056 .1310$ 